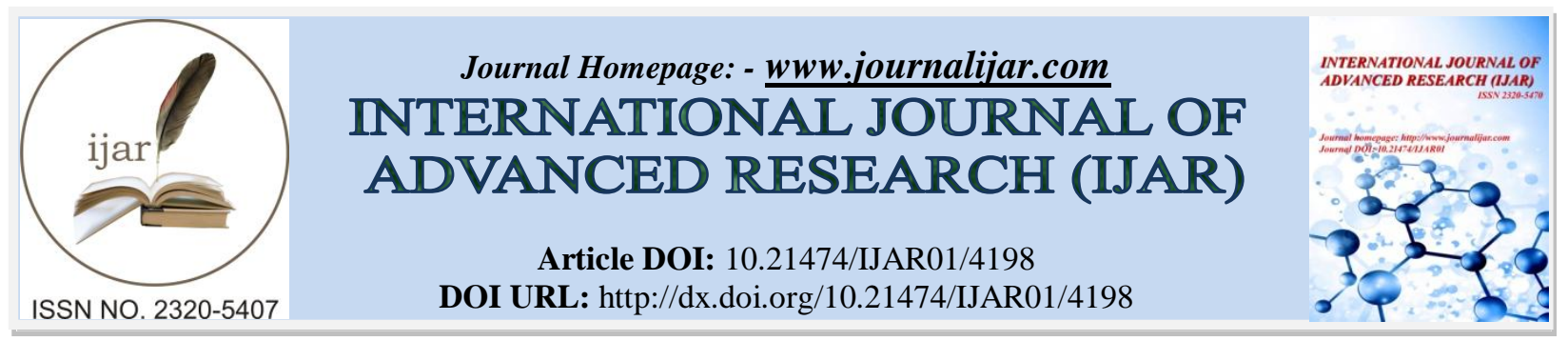

RESEARCH ARTICLE

\title{
RELATIONSHIP BETWEEN DENTAL AGE ACCORDING TO DEMIRJIANAND CERVICAL VERTEBRAE MATURITY IN MYSORE POPULATION.
}

\section{Dr. Karthikeya Patil ${ }^{1}$, Dr. Mahima V.G ${ }^{2}$, Dr. ShasankKundurthy ${ }^{3}$, Dr. BharathiPenumatsa ${ }^{3}$ and Dr. PoornimaChandran ${ }^{3}$.}

1. Professor \& HOD, Dept. of Oral Medicine \& Radiology, J.S.S Dental College \& Hospital, Mysuru, Karnataka.

2. Professor, Dept. of Oral Medicine \& Radiology, J.S.S Dental College \& Hospital, Mysuru, Karnataka.

3. Post Graduate, Oral Medicine \& Radiology, J.S.S Dental College \& Hospital, Mysuru, Karntaka.

\section{Manuscript Info}

Manuscript History

Received: 13 March 2017

Final Accepted: 11 April 2017

Published: May 2017

Key words:-

Cervical Vertebrae, Tooth

Calcifications, Skeletal Maturity.

\section{Abstract}

\section{Introduction:-}

Biological indicators of skeletal maturity refer mainly to somatic changes at puberty, thus emphasizing the known interaction between the development of craniofacial structures and the modifications in the adjacent structures. Somatic maturity is recognized by the annual growth increments in height or weight. The changes of secondary sex characteristics, voice changes in boys and menarche in girls, are characterized as sexual maturity. The usefulness of these two maturity indicators has limited value for the immediate clinical judgment of a patient's maturity stage because these indicators can be applied only after the serial recording of height or the inception of puberty. ${ }^{1}$

The technique for assessing skeletal maturity consists of visual inspection of the developing bones — their initial appearance and their subsequent ossification-related changes in shape and size. Various areas of the skeleton have been used: the foot, the ankle, the hip, the elbow, the hand-wrist, and the cervical vertebrae. ${ }^{2}$

There are some limitations in the interpretation of skeletal maturity from hand-wrist radiographs. The ossification sequence and timing of skeletal maturity within the hand-wrist area show polymorphism and sexual dimorphism, which can limit the clinical predictive use of this method. Moreover, there are concerns about the extra radiation exposure resulting from use of this method, and its use must be questioned if other comparable methods of assessment are available. Finally, events in the hand and wrist are indicators of the peak and the end of the pubertal growth spurt, but these events do not signal the onset of the pubertal growth spurt. . $^{3,4}$

In 1972, Lamparski offered standards of cervical vertebral maturation for boys and girls. Hassel and Farman detailed these cervical vertebra maturation indexessuggesting six stages for cervical vertebral maturation and found a high correlation between cervical vertebral and hand-wrist maturationand stated that the cervical vertebral analysis can be used in the assessment of skeletal maturity ${ }^{5}$. Baccetti et al (2005) has modified their method to six stages based on

Corresponding Author:- Karthikeya Patil.

Address:- Professor \& HOD, Dept. of Oral Medicine \& Radiology, J.S.S Dental College \& 
the concavity of inferior border of cervical vertebrae (C2,C3\& 4 ). The method introduced by Baccetti et al. has been proven reliable and valid enough to substitute the hand wrist analysis. ${ }^{6}$

Dental maturity is also an indicator of the biological maturity of growing children. Dental age can be based on dental eruption or on the stages of tooth calcification observed in radiographs. The latter is more reliable because it is based on distinct details of the tooth shape and it uses the ratio of root length to crown height. The method introduced by Demirjian et al. is one of the common methods used to determine the stages of calcification in several teeth. This method uses an approach to classify tooth mineralization by maturation changes in tooth development rather than just enlargement of the tooth. Since the final tooth size can vary from individual to individual, this system provides a method to categorize teeth not on size, but on certain dental maturity stages that are recognizable.

The correlation between dental maturity \& skeletal maturity in hand wrist bone analysis has been reported. However little is known about association between dental maturity \& cervical vertebrae maturity stages. If a strong association exists between cervical vertebral maturity stages then the stages of dental calcification might be used as a first level diagnostic tool to estimate timing of pubertal growth spurt.

\section{Objectives:-}

The objective of this study was to find the correlation between the developmental stages of mandibular teeth and cervical vertebral maturity stages in Mysuru population sample.

\section{Patients \& Methods:- Study Population:-}

A descriptive cross-sectional study was designed. Panoramic and lateral cephalometric radiographs of 100subjects (50 males \&50 females), ranging in age from six to 15 years, were taken.The radiographs belonged to patients referred to the Department of Orthodontics, J.S.S Dental College \& Hospital. Sample selection was performed according to the convenient sampling method. The inclusion criteria were: (1) Mysuru resident; (2) no systemic disease that could affect general development like hormonal disease; (3) no history of orthodontic treatment; (4) lateral cephalometric and panoramic radiographs available with high clarity and good contrast taken in the same day; (5) no missing or anomalies (trauma, injury, impaction, transposition) in dentition (third molars were not included in this study); (6) no history of trauma or surgery in the neck or orofacial region. We tried to select equal samples for different stages of the cervical vertebral maturation.

\section{Assessment of Dental Age:-}

Panoramic radiographs were studied to determine the calcification stage of permanent mandibular teeth on the left side. We did not consider the maxillary teeth because superimposition of the anatomic structures in this area does not always allow assessment of the accurate developmental stage of the teeth. Third molars were not considered in the assessment. Tooth calcification stages were rated from $\mathrm{A}$ to $\mathrm{H}$ according to the method introduced by Demirjianet al. ${ }^{8}$ The characteristics of stages are (Fig 1)

1. A.Calcification of single occlusal points without fusion of different calcifications.

2. B. Fusion of mineralization points; the contour of the occlusal surface is recognizable.

3. C. Enamel formation is complete at the occlusal surface, and dentin formation has commenced. The pulp chamber is curved, and no pulp horn is visible.

4. D. Crown formation is complete to the level of the cemento-enamel junction. Root formation has commenced. The pulp horns are beginning to differentiate, but the walls of the pulp chamber remain curved.

5. E. The root length remains shorter than the crown height. The walls of the pulp chamber are straight, and the pulp horns are more differentiated than in the stage D. In molars, the radicular bifurcation has started to calcify.

6. F. The walls of the pulp chamber form an isosceles triangle, and the root length is equal to or greater than the crown height. In molars, the bifurcation has developed sufficiently to give the roots a distinct form.

7. G. The walls of the root canal are parallel, but the apical end is partially open. In molars, only the distal root is rated.

8. H. The root apex is completely closed (distal root in molars). The periodontal membrane surrounding the root and apex is uniform in width throughout 


\section{Skeletal Maturity Assessment:-}

Cervical vertebral maturation stage (CVMS) was evaluated on lateral cephalometric radiographs, according to the method described by Baccetti et al. This method, known as CVMS, has been proved useful in the evaluation of skeletal maturation in a single cephalogram. This method analyzes the morphology of the second (C2), third (C3), and fourth (C4) cervical vertebrae and the patient is classified into one of six stages (Fig. 2)

1. CS1: The lower borders of all 3 vertebrae $(\mathrm{C} 2-\mathrm{C} 4)$ are flat. The bodies of both $\mathrm{C} 3$ and $\mathrm{C} 4$ are trapezoid in shape.

2. CS2: A concavity is present at the lower border of $\mathrm{C} 2$. The bodies of both $\mathrm{C} 3$ and $\mathrm{C} 4$ are still trapezoid in shape.

3. CS3: Concavities at the lower borders of both C2 and C3 are present. The bodies of C 3 and $\mathrm{C} 4$ may be either trapezoid or rectangular-horizontal in shape. The growth peak occurs the year after this stage.

4. CS4: Concavities at the lower borders of $\mathrm{C} 2, \mathrm{C} 3$, and $\mathrm{C} 4$ are present. The bodies of both $\mathrm{C} 3$ and $\mathrm{C} 4$ are rectangular-horizontal.

5. CS5: At least 1 of the bodies of $\mathrm{C} 3$ and $\mathrm{C} 4$ is square.If not square, the body of the other cervical vertebra is rectangular-horizontal.

6. CS6: At least 1 of the bodies of $\mathrm{C} 3$ and $\mathrm{C} 4$ is rectangular-vertical in shape

\section{Assessment of Study Sample:-}

All digital radiographs were viewed on the same computer. The stages of cervical vertebra development and tooth formation of each subject were assessed by two trained observer with knowledge of neither age nor gender. The study population will be divided into 5 groups each comprising of 10 subjects in each gender group.

\section{Statistical Methods:-}

The SPSS for Windows release 12.0 was used in calculation of all statistics.

1. Descriptive statistics were obtained by calculating the means and standard deviations of the chronological ages and skeletal ages for the 5 stages of skeletal maturity indicators.

2. The Spearman rank order correlation coefficient was applied to measure the association between skeletal maturational indicators and dental calcification stages of individual teeth, and the statistical significance of the correlation was tested.

3. To study the relationships between the stage of mineralization of the teeth and the stage of skeletal maturation, the percentage distribution of the stages of calcification for each tooth was calculated

\section{Results:-}

Descriptive statistics were obtained by calculating the means and standard deviations of the chronological ages and skeletal ages for the 5 stages of skeletal maturity indicators. The Spearman rank order correlation coefficient was applied to measure the association between skeletal maturational indicators and dental calcification stages of individual teeth, and the statistical significance of the correlation was tested.

To study the relationships between the stage of mineralization of the teeth and the stage of skeletal maturation, the percentage distribution of the stages of calcification for each tooth was calculated.

Pearson correlation coefficient was used to measure the inter-examiner association. $(r=0.899)$ The radiographs of 100 (age range, 6-15 yrs.) participants were studied. Three of them were excluded because of not reaching a definite decision about the stage of cervical vertebral maturation.

Descriptive statistics of calcification stages of the teeth for males and females are given in Table $1 \&$ Table II respectively.

Tooth calcification stage in none of the teeth had a percentage distribution greater than $50 \%$ except Stage $\mathrm{H}$ for molars in case of female subjects. First \& Second Premolars in stage E showed highest distribution. (67.3\% and $64.5 \%$, respectively).

The most frequent cervical vertebrae stages in females were stages 4 (27.0\%), followed by stages $2(22.9 \%)$ and 3 (20.8\%). Males were more frequently in stages $2(38.7 \%)$ and $3(26.5 \%)$, followed by stages $1(16.3 \%)$ and 4 $(8.1 \%)$. (Table III) 


\section{Relationship between Cervical Vertebral Maturation and Tooth Calcification Stages:-}

Spearman rank order correlation coefficients between the dental \& skeletal maturity in the range of $0.32-0.45$. The association ranged from $0.37-0.53$ for male subjects and from $0.40-0.59$ for female subjects. The tooth sequence in order of the highest to the lowest correlation for male subjects was the canine, first premolar, second premolar \& first molar; the corresponding sequence in female subjects was the canine, second premolar, first premolar \& first molar. Table IV shows the Correlation Coefficients between Skeletal and Dental Development Stages in Male and Female Subjects.

\section{Discussion:-}

Adolescence is a period during which the rate of growth acceleration reaches a peak velocity and decelerates until adulthood is reached. This pattern can be found in all individuals but there are marked individual variations in the initiation, duration, rate and amount of growth during this period of life. So it is very important to know the stage of maturation of a patient. Assessing maturational status, whether the pubertal growth spurt of that patient has been reached or completed, can have a considerable influence on diagnosis, treatment goals, treatment planning, and the eventual outcome of orthodontic treatment ${ }^{9}$. This is especially true when clinical considerations are based strongly on the increased or decreased rates of craniofacial growth, such as the timing and use of extra oral traction, the use of functional appliances, extraction vs non-extraction, the selection and execution of orthodontic retention, and the timing of orthognathic surgery. ${ }^{10}$

Conventional prediction indicators of maturation overestimate a child's developmental stage and, consequently, underestimate growth potential. Conversely, comparisons of a child's status with published standards from other countries might overestimate the degree of developmental delay or precocity. Racial variations in the relationships between skeletal maturity established by hand-wrist radiographs and cervical vertebrae were previously reported. But direct comparison between Demirjian's method and the improved CVM method was not found in literature. Therefore, the purpose of this study was to investigate the relationship between dental age evaluated using Demirjian's method and skeletal maturity determined by the CVM method.

Panoramic radiographs are routinely available in orthodontic clinics and the method of dental age determination described by Demirjian is based on the calcification stage of the seven left mandibular teeth, whichare clearly visible on such radiographs. The criteria of the method comprise the shape and proportion of root length (using the relative value to crown height rather than absolute tooth length) and thus the influence of radiographic projection is minimal.

In most of the recent studies, skeletal maturity was assessed by means of hand wrist radiographs (no matterwhich method of radiograph evaluation was used) due to the presence of different types of bones in this anatomical region. However, recently, there has been growing interest in thestages of the maturity of the cervical vertebrae as a biological index of individual skeletal maturity. One of the main reasons for the increasing popularity of this method is avoidance of additional radiation exposure to the patient, as cervical vertebrae can be assessed on cephalometric radiographs, frequently used in orthodontic diagnostics. The current CVM method, consisting of six maturity stages defined by means of visual evaluation of morphology of three cervical vertebrae $(\mathrm{C} 2, \mathrm{C} 3$, and $\mathrm{C} 4$ ), is that most frequently used for this purpose. Validity of the method, irrespective of the approach or the studied population, had been confirmed by comparisons with skeletal age estimated by means of hand and wrist radiographs. ${ }^{6}$

In a similar study Ingrid Różyło-Kalinowska et Al. in polish children found that there was consistent earlier occurrence (by about 6 months) of each CS was observed in females. A moderate, but statistically significant, correlation between Demirjian's dental developmental stages and CS was determined. The level of the correlation was different for individual teeth: the teeth showing the highest relationship with CVM were the second premolars and canines (in female and male subjects, respectively). ${ }^{11}$

Krailassiri et al. (2002), in a study of Thai children, determined the development of teeth using Demirjian's method and skeletal maturity by means of hand wrist radiographs analysis (Greulich and Pyle atlas, Fishman system). Those authorsanalyzed development of the left mandibular canines, first and second premolars, and second and third molars. The relationship between dental maturity and skeletal development was the strongest for the second premolar. ${ }^{12}$ 
In the Turkish population, the second molar presented the highest relationship with skeletal maturity (boys: $\mathrm{R}=$ 0.826 and girls: $\mathrm{R}=0.706)$. The lowest correlation was noted for the third molar, both in girls $(\mathrm{R}=0.49)$ and boys $(\mathrm{R}=0.414)^{13}$. Uysal et al. (2005) also analyzed the mean chronological agerelated to all skeletal maturity stages and an earlier occurrence of all, but the last stage $(\mathrm{Ru})$, was noted in girls ${ }^{4}$. This observation is in concordance with the comparison of chronological age with CS maturity stages in the current study. Earlier skeletal maturation (approximately 6 months) was observed in females, which is in agreement with the results of Coutinho et al. $(1993)^{14}$ andKrailassiriet al. (2002). On the other hand, acceleration of dental age was observed in children of Mazovia (Central Poland) (Różyło-Kalinowska et al., 2008).

However, the simplicity of the evaluation of the development of teeth as well as the widespread availability of intraand extra oral radiographs is decisive in the application of the dental maturity method as a tool for initial assessment of the level of skeletal maturity of a child. It must be remembered that this tool cannot be used as the only measure of development, especially in atypically developing patients, such as those with endocrine disorders, congenital diseases, or other signs and symptomsof developmental disharmonies. In such subjects, full information on developmental age is relevant only when simultaneous estimation of several indices is performed.

The present results are preliminary due to the fact that it is the first study to compare the CVM method of skeletal maturityevaluation with dental development indices in Mysuru population. Moreover, the material consisting of 100 patients is not fully representative and for epidemiological purposes, the studied group should be larger and balanced regarding gender.

Table I:- Descriptive statistics of Tooth Calcification Stages (Males)

\begin{tabular}{|l|l|l|l|l|}
\hline Stage & Canine (\%) & I Premolar (\%) & II Premolar (\%) & I Molar (\%) \\
\hline C & 0 & 0 & $1(2)$ & 0 \\
\hline D & 0 & $3(5.9)$ & $2(4.1)$ & $9(18.4)$ \\
\hline E & $11(21.6)$ & $17(33.3)$ & $16(32.7)$ & $1(2.0)$ \\
\hline F & $15(29.4)$ & $10(19.6)$ & $9(18.4)$ & $3(6.1)$ \\
\hline G & $13(25.5)$ & $5(9.8)$ & $10(20.4)$ & $15(30.6)$ \\
\hline H & $10(19.6)$ & $14(27.5)$ & $11(22.4)$ & $21(42.9)$ \\
\hline
\end{tabular}

Table II:-Descriptive statistics of Tooth Calcification Stages (Females)

\begin{tabular}{|l|l|l|l|l|}
\hline Stage & Canine (\%) & I Premolar (\%) & II Premolar (\%) & I Molar (\%) \\
\hline C & 0 & $1(2.0)$ & 0 & 0 \\
\hline D & $1(2.0)$ & $4(8.0)$ & $4(8.0)$ & 0 \\
\hline E & $3(6.0)$ & $14(28.0)$ & $17(34.0)$ & 0 \\
\hline F & $20(40.0)$ & $6(12.0)$ & $5(10.0)$ & $3(6.0)$ \\
\hline G & $2(4.0)$ & $4(8.0)$ & $2(4.0)$ & $18(36.0)$ \\
\hline H & $22(44.0)$ & $19(38.0)$ & $20(40.0)$ & $27(54.0)$ \\
\hline
\end{tabular}

Table III:-Cervical Vertebrae Maturity Staging in each group

\begin{tabular}{|l|l|l|l|}
\hline CS Stage & No. $(\%)$ & Males & Females \\
\hline CS 1 & $10(10.3)$ & 8 & 2 \\
\hline CS2 & $30(30.9)$ & 19 & 11 \\
\hline CS3 & $23(23.7)$ & 13 & 10 \\
\hline CS4 & $17(17.5)$ & 4 & 13 \\
\hline CS5 & $11(11.3)$ & 3 & 8 \\
\hline CS6 & $6(6.1)$ & 2 & 4 \\
\hline
\end{tabular}

Table IV:Correlation Coefficients between Skeletal and Dental Development Stages in Male and Female Subjects

\begin{tabular}{|c|c|c|}
\hline \multirow[t]{2}{*}{ Tooth } & \multicolumn{2}{|c|}{ Correlation Coefficients } \\
\hline & Females & Males \\
\hline Canine & 0.59 & 0.53 \\
\hline
\end{tabular}




\begin{tabular}{|l|l|l|}
\hline I Premolar & \multicolumn{1}{|c|}{${ }^{*}{ }^{*}$} & $0.44^{*}$ \\
\hline II Premolar & $0.45^{*}$ & $0.41^{*}$ \\
\hline I Molar & $0.51^{*}$ & $0.37^{*}$ \\
\hline
\end{tabular}

Fig. 1

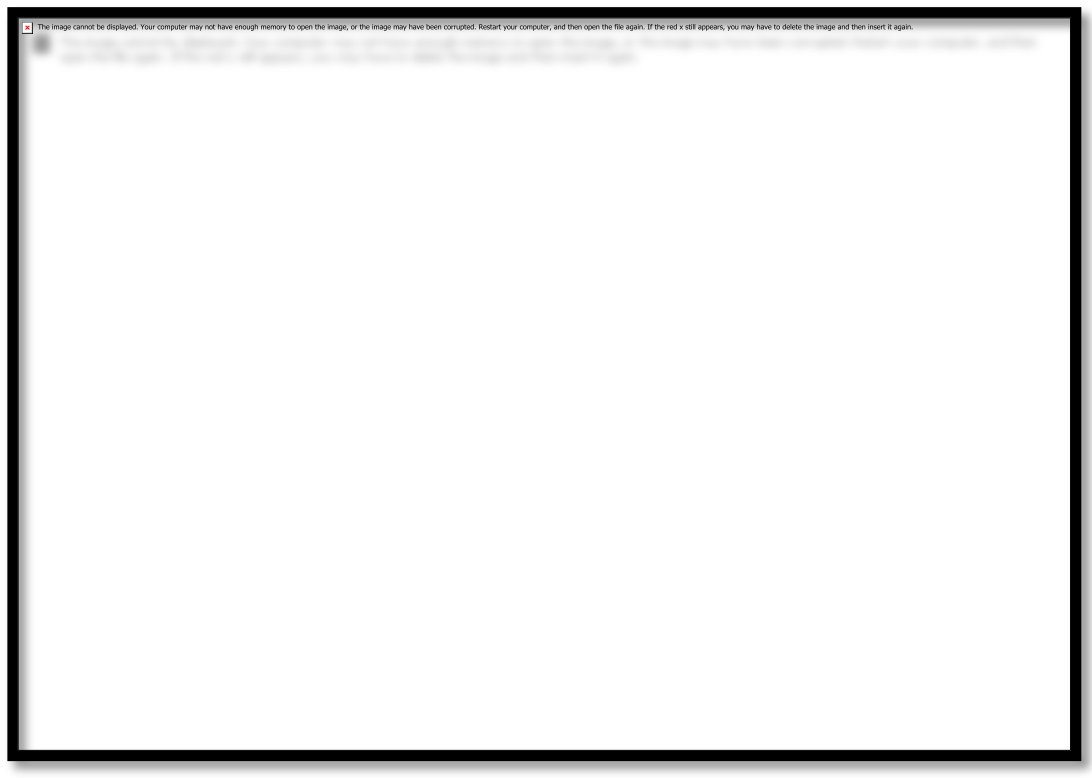

Fig 2

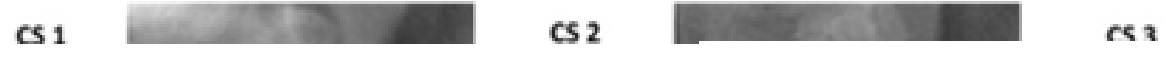




\section{References:-}

1. Krogman WM. Biological timing and the dento-facial complex.J Dent Child. 1968;35:328-341.

2. Franchi L, Baccetti T, McNamara JA Jr. The cervical vertebralmaturation method: some need for clarification. Am J OrthodDentofacialOrthop 2003;123:19-20A.

3. Hassel B, Farman AG. Skeletal maturation evaluation usingcervical vertebrae. Am J OrthodDentofacialOrthop1995;107(1):58-66.

4. Uysal T, Ramoglu SI, Basciftci FA, Sari Z. Chronologic age andskeletal maturation of the cervical vertebrae and hand-wrist Is there a relationship? Am J OrthodDentofacialOrthop

5. Lamparski D. Skeletal age assessment utilizing cervicalvertebrae [Unpublished master's thesis]. Pittsburgh:University of Pittsburgh 1972.

6. Baccetti T, Franchi L, McNamara Jr JA. The Cervical VertebralMaturation (CVM) method for the assessment of optimaltreatment timing in dentofacial orthopedics. SeminOrthod2005;11(3):119-29.

7. Demirjian A, Buschang P H, TanguayR,Kingnorth Patterson D 1985 Interrelationships among measures of somatic, skeletal, dental, and sexual maturity. American Journal of Orthodontics 88: 433-438

8. Demirjian A, Goldstein H, Tanner M 1973 A new system for dental age assessment. Human Biology 45: 211227

9. Grave B, Brown t 1976 Skeletal ossification and the adolescent growth spurt. American Journal of Orthodontics 69: 611-619

10. Green L J 1961 The interrelationships among height, weight and chronological, dental and skeletal ages. Angle Orthodontist 31: 189-193

11. Różyło-Kalinowska I, Kolasa-Rączka A, Kalinowski P. Relationship between dental age according to Demirjian and cervical vertebrae maturity in Polish children. The European Journal of Orthodontics. 2011 Feb 1;33(1):75-83.

12. Krailassiri S, Anuwongnukroh N, Dechkunakorn S. Relationships between dental calcification stages and skeletal maturity indicators in Thai individuals. The Angle orthodontist. 2002 Apr;72(2):155-66.

13. Başaran G, Özer T, Hamamcı N. Cervical vertebral and dental maturity in Turkish subjects. American Journal of Orthodontics and Dentofacial Orthopedics. 2007 Apr 30;131(4):447-e13.

14. Coutinho S, Buschang P H , Miranda F 1993 Relationships between mandibular canine calci $\square$ caton stages and skeletal maturity. AmericanJournal of Orthodontics and Dentofacial Orthopedics 104: 262 - 268. 